\title{
Adult spinal deformity and its relationship with height loss: a 34-year longitudinal cohort study
}

\author{
Mutsuya Shimizu ${ }^{1 *}$ (D), Tetsuya Kobayashi ${ }^{1}$, Hisashi Chiba², Issei Senoo ${ }^{1}$, Hiroshi Ito ${ }^{1}$, Keisuke Matsukura ${ }^{3}$ and \\ Senri Saito ${ }^{3}$
}

\begin{abstract}
Background: Age-related height loss is a normal physical change that occurs in all individuals over 50 years of age. Although many epidemiological studies on height loss have been conducted worldwide, none have been longterm longitudinal epidemiological studies spanning over 30 years. This study was designed to investigate changes in adult spinal deformity and examine the relationship between adult spinal deformity and height loss.

Methods: Fifty-three local healthy subjects (32 men, 21 women) from Furano, Hokkaido, Japan, volunteered for this longitudinal cohort study. Their heights were measured in 1983 and again in 2017. Spino-pelvic parameters were compared between measurements obtained in 1983 and 2017. Individuals with height loss were then divided into two groups, those with degenerative spondylosis and those with degenerative lumbar scoliosis, and different characteristics were compared between the two groups.

Results: The mean age of the subjects was 44.4 (31-55) years at baseline and 78.6 (65-89) years at the final followup. The mean height was $157.4 \mathrm{~cm}$ at baseline and $153.6 \mathrm{~cm}$ at the final follow-up, with a mean height loss of 3.8 $\mathrm{cm}$ over 34.2 years. All parameters except for thoracic kyphosis were significantly different between measurements taken in 1983 and 2017 ( $p$ < 0.05). Height loss in both sexes was related to changes in pelvic parameters including pelvic incidence-lumbar lordosis $(R=0.460 p=0.008$ in men, $R=0.553 p=0.012$ in women), pelvic tilt ( $R=0.374$ $p=0.035$ in men, $R=0.540 p=0.014$ in women), and sagittal vertical axis $(R=0.535 p=0.002$ in men, $R=0.527 p=$ 0.017 in women). Greater height loss was more commonly seen in women $(p=0.001)$ and in patients with degenerative lumbar scoliosis ( $p=0.02$ ).

Conclusions: This longitudinal study revealed that height loss is more commonly observed in women and is associated with adult spinal deformity and degenerative lumbar scoliosis. Height loss is a normal physical change with aging, but excessive height loss is due to spinal kyphosis and scoliosis leading to spinal malalignment. Our findings suggest that height loss might be an early physical symptom for spinal malalignment.
\end{abstract}

Keywords: Adult spinal deformity, Height loss, Lumbar lordosis, Spondylosis, Lumbar scoliosis, Thoracic kyphosis, Pelvic tilt, Sagittal vertical axis

\footnotetext{
* Correspondence: smzspine@asahikawa-med.ac.jp

'Department of Orthopaedic Surgery, Asahikawa Medical University, 2-1E

Midorigaoka, Asahikawa, Hokkaido 078-8510, Japan

Full list of author information is available at the end of the article
}

C C The Author(s). 2020 Open Access This article is licensed under a Creative Commons Attribution 4.0 International License, which permits use, sharing, adaptation, distribution and reproduction in any medium or format, as long as you give appropriate credit to the original author(s) and the source, provide a link to the Creative Commons licence, and indicate if changes were made. The images or other third party material in this article are included in the article's Creative Commons licence, unless indicated otherwise in a credit line to the material. If material is not included in the article's Creative Commons licence and your intended use is not permitted by statutory regulation or exceeds the permitted use, you will need to obtain permission directly from the copyright holder. To view a copy of this licence, visit http://creativecommons.org/licenses/by/4.0/. The Creative Commons Public Domain Dedication waiver (http://creativecommons.org/publicdomain/zero/1.0/) applies to the data made available in this article, unless otherwise stated in a credit line to the data. 


\section{Background}

Population aging is seen worldwide. Thus, it is important that an appropriate quality of life (QOL) is maintained for the entire lifespan of any individual. Adult spinal deformity (ASD) can affect the sagittal alignment of the spine, which may impact the QOL [1-3]. The ultimate aim of ASD treatment, even in younger patients, is to ensure that patients are ambulant without requiring a cane or handrail for support. ASD affects muscular strength leading to changes in the range of motion of the trunk, lower extremities, and the whole body $[4,5]$.

Individuals with ASD will receive lower scores in all domains of the 36-Item Short Form Survey as they age, while in other chronic conditions such a decline with age is not observed [6]. For evaluating ASD, ideal values for parameters including pelvic incidence-lumbar lordosis (PI-LL), pelvic tilt (PT), and sagittal vertical axis (SVA) were proposed by the International Spine Study Group [3], and target values have been modified to include age and surgical results [7-9].

Height loss is an age-related physical change that occurs in all individuals over 50 years and that elderly people are aware of [10], and is correlated with osteoporosis [11, 12], vertebral fracture [13-16], and mortality [17]. Decreased QOL is also reportedly associated with height loss according to the EQ-5D scores [18].

Although both ASD and height loss are associated with aging, no study has examined the relationship between height loss and ASD, based on the abovementioned parameters. Besides, many epidemiological studies were conducted on height loss worldwide; however, over the 30 years longitudinal no epidemiological studies have been conducted in this field. The purpose of this 34-year longitudinal cohort study was to investigate the relationship between ASD and height loss in community-based volunteers and to determine the effects of sex.

\section{Methods}

\section{Cohort selection}

This study is a follow-up of an epidemiological study by Takemitsu et al. in 1983, in Furano, Hokkaido, Japan [19]. Of the 249 adult volunteers who lived locally, and who had participated in the original study in 1983, we included 53 volunteers ( $32 \mathrm{men} / 21$ women) in 2017 for this follow-up 34-year longitudinal study. The subjects were living in an agriculture area and trunk bending positions were a requirement of their job. The initial recruitment of the cohort was done by sending invitations to all rural residents of the area using the information in a resident ledger. In the current study, those who had participated in the initial study were contacted by phone and invited to take part in this survey.
The inclusion criteria were as follows: no spinal or major joint surgery between 1983 and 2017, ability to walk independently to our hospital for the present study, and aged less than 55 years in 1983 in consideration of current age.

The exclusion criteria were being unable to stand in the correct posture during radiography, unable to tolerate the pain, osteoporosis fracture, paralysis of trunk or lower extremity, and not consenting to the study. Figure 1 presents the subject details.

\section{Spinal X-ray}

The subjects underwent radiography of the entire spine in an upright position in 1983 and 2017. The participants were instructed to stand in a relaxed position and look straight ahead, with their fists at the level of the clavicle.

The heights of all subjects were measured in meters without their shoes, with the back of their head, buttocks, back, and heels against an upright board. The back muscle was stretched as much as possible, and feet were supinated by about $30^{\circ}$. Participants with height loss were then selected and divided into two groups: those with $\leq 4 \mathrm{~cm}$ (small height less, $\mathrm{S}$ group) and those with $>4 \mathrm{~cm}$ (large height loss, L group) loss of height.

\section{Radiographic parameters}

Standardized radiographic measurements of sagittal spino-pelvic parameters included thoracic kyphosis (TK), lumbar lordosis (LL), PT, pelvic incidence (PI), sacral slope (SS), and SVA [20, 21] (Fig. 2). ASD was radiologically evaluated based on the SRS-Schwab ASD classification sagittal modifiers [3]. Degenerative spondylosis (DS) was determined as 5\% percent slip [22] and degenerative lumbar scoliosis (DLS) was identified based on the Cobb method [23] with a scoliotic angle of more than $10^{\circ}$ [24-26].

\section{Statistical analysis}

All statistical analyses were performed using SPSS Statistics version 12 (IBM, Tokyo, Japan). All data are expressed as mean and range. Variables that were normally distributed were analyzed using the Shapiro-Wilk test. When measured variables were found to have a non-normal distribution, Spearman's correlation was used to evaluate the association between height loss and spino-pelvic parameters. Sub-analyses were performed to evaluate the association between height loss and sex, DS, and DLS.

In comparing the height loss between the 2 groups, if lack of normality was rejected, a t-test was performed. If the lack of normality was significant, the Wilcoxon signed rank test or Mann-Whitney U-test was 


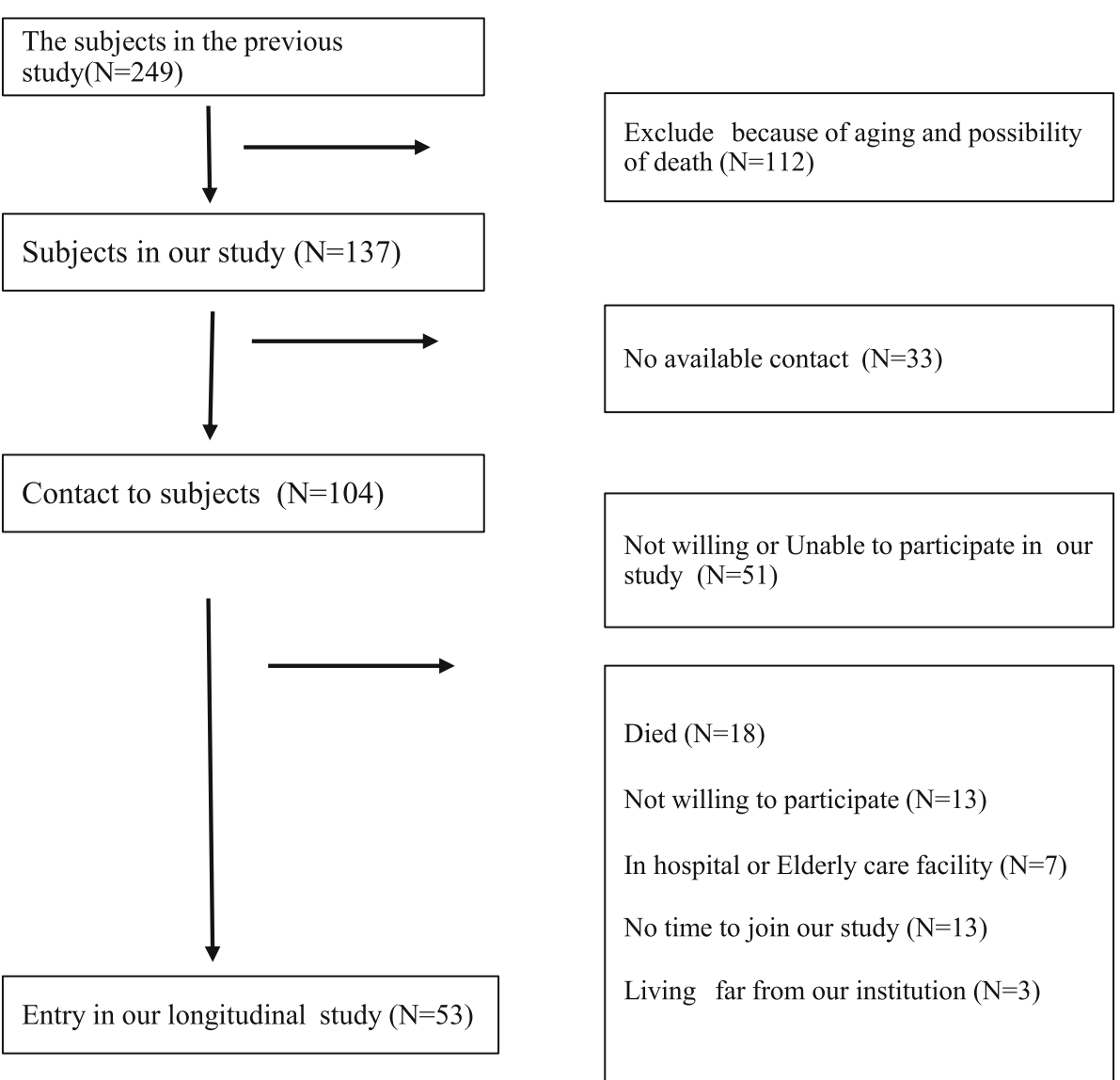

Fig. 1 Flowchart of the enrolment process in our study. We approached 104 local subjects, of which 53 agreed to participate in this study

performed, as appropriate. A $P$-value of $<0.05$ was considered statistically significant.

\section{Results}

The mean age of the subjects was 44.4 (31-55) years at baseline and 78.6(65-89) years at the final follow-up. The mean follow-up period was 34.2 (34-34.4) years. The mean height of the subjects was 157.4 (140-170) $\mathrm{cm}$ at baseline and $153.6(132-169) \mathrm{cm}$ at the final follow-up, with a mean height loss of $3.8 \mathrm{~cm}$ over 34 years.

A summary of longitudinal changes in radiographic variables from baseline to the final follow-up is presented in Table 1. Statistical analyses revealed significant longitudinal changes in all parameters except for body mass index and TK.

Spino-pelvic parameters including PI-LL, PT, and SVA were significantly associated with height loss in both male and female subjects (Table 2). Based on our definition for DS, 7 participants were in the DS(+) group and 46 participants in the DS(-) group. Upon assessing for DLS, 26 participants were in the DLS(+) group and 27 in the DLS(-) group. The large height loss group had more patients with DLS, but there were no significant differences in height loss between the DS groups (Tables 3, 4). When we compared height loss in terms of sex, $31 \%$ of the participants in the large height loss group were men and $76 \%$ were women, suggesting that female subjects had greater height loss than male subjects (Table 5 ).

\section{Discussion}

To the best of our knowledge, this 34-year longitudinal cohort study is the first to examine the relationship between ASD and height loss. We observed that height loss was significantly correlated with changes in the sagittal modifiers of the SRS-Schwab classification [3]. Our results showed that height loss was more common in female subjects and was related to coronal and sagittal deformities observed in DLS and ASD.

There was no significant change in the values for TK over 34 years, which is similar to the findings of Kobayashi et al. who also reported small changes in TK over their study period of 12.3 years [4]. On the other hand, Diebo et al. reported a wider range for TK, with spinal malalignment ranging from hyper- to hypokyphosis [27], 


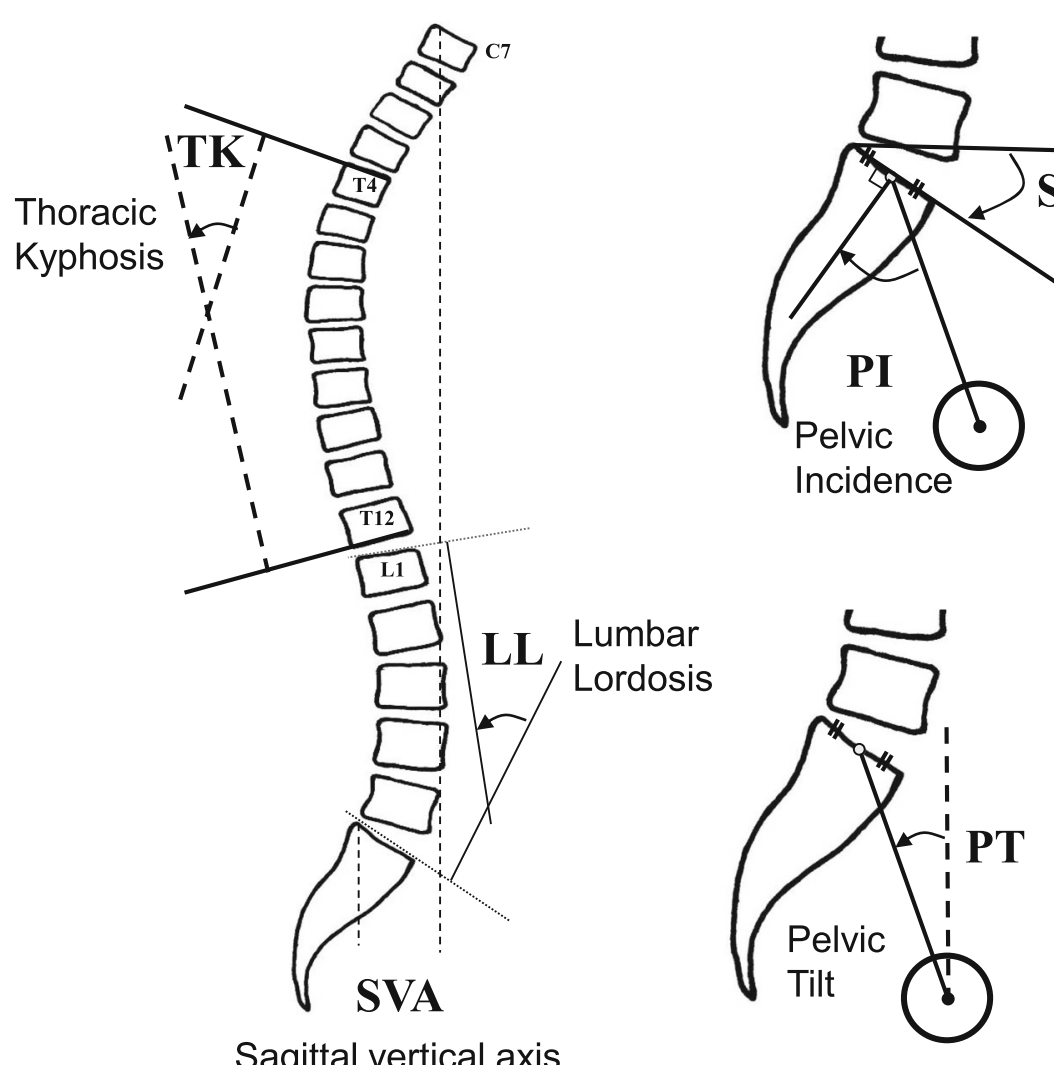

Fig. 2 Radiographic measurements of spinopelvic alignment. Left: thoracic kyphosis (TK), lumbar lordosis (LL), sagittal vertical axis (SVA). Right: pelvic incidence (PI), sacral slope (SS), and pelvic tilt (PT)

which might have been because of the wide range of spine flexibility, disc degenerations, and age observed in their cohort. Kamimura also showed that spinal kyphosis was significantly associated with height loss in elderly Japanese women [28]. Their report used self-reported

Table 1 Changes in characteristics of participants after 34 years ${ }^{1}$

\begin{tabular}{llll}
\hline Variables & Baseline & Final follow-up & $\boldsymbol{P}$ value \\
\hline Age (years) & $44.4(31$ to 55$)$ & $78.6(65$ to 89$)$ & $<0.0001$ \\
Height $(\mathrm{cm})$ & $157.4(140$ to 170$)$ & $153.6(132$ to 169$)$ & $<0.0001$ \\
Body weight $(\mathrm{kg})$ & $61.9(44$ to 85$)$ & $58.0(38$ to 87$)$ & $<0.0001$ \\
BMI $\left(\mathrm{kg} / \mathrm{m}^{2}\right)$ & $24.9(20$ to 31$)$ & $24.4(18$ to 30$)$ & 0.203 \\
TK & $35.4(16$ to 66$)$ & $34.3(2$ to 69$)$ & 0.515 \\
LL & $55.1(32$ to 79$)$ & $32.4(-32$ to 77$)$ & $<0.0001$ \\
PT & $14.4(0$ to 39$)$ & $25.9(4$ to 54$)$ & $<0.0001$ \\
PI & $56.0(33$ to 76$)$ & $54.4(27$ to 78$)$ & 0.015 \\
PI-LL & $0.9(-25$ to 30$)$ & $21.1(-15$ to 84$)$ & $<0.0001$ \\
SS & $41.4(26$ to 58$)$ & $28.7(0$ to 48$)$ & $<0.0001$ \\
SVA & $4.3(-40$ to 67$)$ & $63.9(-31$ to 282$)$ & $<0.0001$ \\
\hline
\end{tabular}

${ }^{1}$ Data are presented as mean (range)

${ }^{2} P$ value $<0.05$ was considered significant

Abbreviations: BMI body mass index, TK thoracic kyphosis, LL lumbar lordosis, PT pelvic tilt, PI pelvic incidence, SS sacral slope, SVA sagittal vertical axis categories of kyphosis, which though simple, was not objective.

Aging-related spinal changes begin with degenerative inter-vertebral disk changes [29]. Later, height loss may occur because of several causes, such as progression of intervertebral disk degeneration, vertebral deformity or fracture, and decreased muscle strength, all of which are found in subjects with ASD. Hence, radiographic parameters are useful tools for subjective evaluation of ASD, since changes in SVA, PT, and PI-LL might also lead to height loss.

The main cause for DLS is disc degeneration, leading to decreased disc height and the progression of DLS. Faraj et al. provided strong evidence that increased disc degeneration in DLS, the first sign of height loss, leads to progression of the lumbar scoliosis curve [30]. In the current study, more subjects were diagnosed with DLS compared to the general population. Such a high incidence might be due to the fact that most people living in this area are agricultural workers in the area, and the inherent requirement of the job is that they should remain in a forward bending position for long periods of time. This position increases the load on the lumbar spine, 
Table 2 Spearman's correlations among different parameters in male and female participants

\begin{tabular}{lllll}
\hline Variables & Male & & Female \\
\cline { 2 - 5 } & Correlation coefficient & $\boldsymbol{P}$ value & & \\
\hline Weight & 0.438 & 0.012 & 0.187 & 0.427 \\
BMI & 0.302 & 0.093 & 0.136 & 0.567 \\
TK & -0.058 & 0.752 & -0.244 & 0.300 \\
LL & 0.438 & 0.014 & 0.530 & 0.016 \\
PT & 0.374 & 0.035 & 0.540 & 0.014 \\
PI & 0.165 & 0.366 & 0.06 & 0.801 \\
PI-LL & 0.460 & 0.008 & 0.553 & 0.012 \\
SS & -0.432 & 0.014 & -0.635 & 0.003 \\
SVA & 0.535 & 0.002 & 0.527 & 0.017 \\
\hline P & & &
\end{tabular}

${ }^{1} P$ value $<0.05$ was considered significant

Abbreviations: BMI body mass index, TK thoracic kyphosis, LL lumbar lordosis, PT pelvic tilt, PI pelvic incidence SS sacral slope, SVA sagittal vertical axis

which can be a cause for the higher prevalence of degenerative scoliosis in this cohort.

Furthermore, it is reported that LL decreases and SVA increases as degenerative scoliosis progresses [31], with preceding coronal and sagittal deformities also influencing each other [29]. Hence, scoliosis is reportedly one of the factors associated with height loss of $3 \mathrm{~cm}$ or more [11].

In our study, height loss was more pronounced in women, which might be because of the differences in the skeletal structure between the sexes. It should be noted that these differences may be observed over time; however, to date, no prospective studies have confirmed this change, although Takemitsu et al. have reported a higher prevalence of lumbar degenerative kyphosis in women in a previous study [19], which might explain the higher prevalence of height loss in women than in men. Besides, women are reportedly more likely to experience degenerative disk changes [32]. Furthermore, while vertebral deformity is expected to occur in elderly subjects [32], women were at a higher risk of vertebral fractures associated with aging. Reduced muscular strength due to advanced age and vertebral fractures because of osteoporosis mainly occur in women, and the female sex is a risk factor for DLS [33]. Therefore, ASD and height loss are more commonly seen in women. In a 10-year prospective study, Yoshimura reported that in men, height loss did not differ significantly between those in the 40-49 years age group

Table 3 Comparison between degenerative spondylosis and height loss

\begin{tabular}{llll}
\hline & $L$ group $(>4 \mathrm{~cm})[\boldsymbol{N}=26]$ & S group $(\leq 4 \mathrm{~cm})[\boldsymbol{N}=27]$ & Total \\
\hline DS $(+)$ & 2 & 5 & 7 \\
DS $(-)$ & 24 & 22 & 46 \\
Total & 26 & 27 & 53 \\
\hline
\end{tabular}

$P$-value $=0.226$ using a $x^{2}$-test.

$D S$ degenerative spondylosis. and the 70-79 years age group, but in women, height loss was more common in the $70-79$ years age group than in other age groups (40-49 and 60-69 years) [34]. These results suggest that height loss progresses rapidly with age in women.

The complication rate of ASD surgery is high [35, 36], and early care for maintaining sagittal alignment is one of the most important treatments. The use of bisphosphonate and denosumab as an early treatment to maintain spinal alignment and to prevent height loss [37, 38], especially when combined with the reportedly effective physical treatment for spinal deformity, may result in delaying surgical treatment $[39,40]$.

One of the strengths of our study is that height was measured accurately in both times, while in previous reports, participants recalled their previous heights from memory, which might have led to inaccurate height recording [11]. Our study also had several limitations. Firstly, the number of subjects was low, which affected the findings of our study. However, follow-up periods were longer than previously reported studies. Secondly, our study did not examine QOL score, or living status in relation to height loss. Thirdly, subjects were living in an agriculture area and trunk bending positions were a requirement of their job. Therefore, we cannot generalize our results to other populations. Large longitudinal studies including subjects from more diverse backgrounds are required to address these limitations.

Table 4 Comparison between degenerative lumbar scoliosis and height loss

\begin{tabular}{llll}
\hline & L group $(>4 \mathrm{~cm})[\boldsymbol{N}=26]$ & S group $(\leq 4 \mathrm{~cm})[\boldsymbol{N}=27]$ & Total \\
\hline $\operatorname{DLS}(+)$ & 17 & 9 & 26 \\
DLS $(-)$ & 9 & 18 & 27 \\
Total & 26 & 27 & 53 \\
\hline
\end{tabular}

$P$-value $=0.02$ using a $x^{2}$-test.

$D L S$ degenerative lumbar scoliosis. 
Table 5 Comparison of height loss between the sexes

\begin{tabular}{llll}
\hline & $L$ group $(>4 \mathrm{~cm})[\boldsymbol{N}=26]$ & $S$ group $(\leq 4 \mathrm{~cm})[\boldsymbol{N}=27]$ & Total \\
\hline Male (\%) & $10(31 \%)$ & $22(69 \%)$ & 32 \\
Female (\%) & $16(76 \%)$ & $5(24 \%)$ & 21 \\
Total & 26 & 27 & 53
\end{tabular}

$P$ value $=0.001$ using a $X^{2}$-test.

\section{Conclusions}

We observed that height loss was related to ASD and DLS. Height loss was more prominent in women than in men. Height loss is a normal physical change with aging, but excessive height loss is mainly due to the occurrence of spinal kyphosis and scoliosis leading to spinal malalignment. Hence, height loss may be considered as a physical symptom for spinal malalignment.

\section{Abbreviations}

QOL: Quality of life; ASD: Adult spinal deformity; PI-LL: Pelvic incidencelumbar lordosis; TK: Thoracic kyphosis; LL: Lumbar lordosis; PT: Pelvic tilt; PI: Pelvic incidence; SS: Sacral slope; SVA: Sagittal vertical axis;

DS: Degenerative spondylosis; DLS: Degenerative lumbar scoliosis

\section{Acknowledgements}

The authors especially thank the staff of Furano kyokai hospital for their corporation and dedication to the collection of data for this study.

\section{Authors' contributions}

M.S. wrote the first draft of the manuscript. M.S., T.K., H.C., I.S., K.M., S.S collected the clinical data. T.K., and H.I organized and designed this study. All authors have reviewed the manuscript and provided constructive input. The author(s) read and approved the final manuscript.

\section{Funding}

The study did not receive any financial support from any public, private, or non-for-profit organization.

\section{Availability of data and materials}

The datasets used for the current study are available from the corresponding author upon reasonable request.

\section{Ethics approval and consent to participate}

This study was approved by the ethical review board of Asahikawa Medical University (Approval number: 16149). All individuals included in this study provided verbal and written informed consent in 2017.

\section{Consent for publication}

Not applicable.

\section{Competing interests}

The authors declare that they have no competing interest.

\section{Author details}

${ }^{1}$ Department of Orthopaedic Surgery, Asahikawa Medical University, 2-1E Midorigaoka, Asahikawa, Hokkaido 078-8510, Japan. ${ }^{2}$ Department of Rehabilitation and Physical Therapy, Furano Kyokai Hospital, Furano, Japan.

${ }^{3}$ Department of Orthopaedic Surgery, Furano Kyokai Hospital, Furano, Japan.

Received: 16 January 2020 Accepted: 25 June 2020

Published online: 01 July 2020

\section{References}

1. Glassman SD, Bridwell K, Dimar JR, Horton W, Berven S, Schwab F. The impact of positive sagittal balance in adult spinal deformity. Spine. 2005;30: 2024-9.
2. Schwab F, Dubey A, Pagala M, Gamez L, Farcy JP. Adult scoliosis: a health assessment analysis by SF-36. Spine. 2003;28:602-6.

3. Schwab F, Ungar B, Blondel B, Buchowski J, Coe J, Deinlein D, et al. Scoliosis Research Society-Schwab adult spinal deformity classification: a validation study. Spine. 2012;37:1077-82.

4. Kobayashi T, Chiba H, Jimbo S, Senoo I, Shimuzu M, Atsuta Y, et al. Clinical, physical, and radiographic analyses of lumbar degenerative kyphosis and spondylolisthesis among community-based cohort. Eur Spine J. 2016;25: 2384-9.

5. Shimizu M, Kobayashi T, Chiba H, Jimbo S, Sinoh I, Ito H. Adult spinal deformity and its relationship with hip range of motion: a cohort study of community-dwelling females. Spine J. 2019;19:1202-9.

6. Pellise F, Vila-Casademunt A, Ferrer M, Domingo-Sabat M, Bago J, PerezGrueso FJ, et al. Impact on health-related quality of life of adult spinal deformity (ASD) compared with other chronic conditions. Eur Spine J. 2015; 24:3-11.

7. International Spine Study Group, Schwab FJ, Diebo BG, Smith JS, Hostin RA Shaffrey $\mathrm{Cl}$, et al. Fine-tuned surgical planning in adult spinal deformity: determining the lumbar lordosis necessary by accounting for both thoracic kyphosis and pelvic incidence. Spine J. 2014;14:S73.

8. Diebo B, Varghese J, Lafage R, Schwab FJ, Lafage V. Sagittal alignment of the spine: what do you need to know? Clin Neurol Neurosurg. 2015;139: 295-301.

9. Jalai CM, Cruz DL, Diebo BG, Poorman G, Lafage R, Bess S, et al. Full body analysis of age-adjusted alignment in adult spinal deformity patients and lower-limb compensation. Spine. 2017;42:653-61.

10. Cline MG, Meredith KE, Boyer JT, Burrows B. Decline of height with age in adults in a general population sample: estimating maximum height and distinguishing birth cohort effects from actual loss of stature with aging. Hum Biol. 1989:61:415-25.

11. Briot K, Legrand E, Pouchain D, Monnier S, Roux C. Accuracy of patientreported height loss and risk factors for height loss among postmenopausal women. CMAJ. 2010;182:558-62.

12. Yoh K, Kuwabara A, Tanaka K. Detective value of historical height loss and current height/knee height ratio for prevalent vertebral fracture in Japanese postmenopausal women. J Bone Miner Metab. 2014;32:533-8.

13. Siminoski K, Jiang G, Adachi JD, Hanley DA, Cline G, loannidis G, et al. Accuracy of height loss during prospective monitoring for detection of incident vertebral fractures. Osteoporos Int. 2005;16:403-10.

14. Mikula AL, Hetzel SJ, Binkley N, Anderson PA. (2017) validity of height loss as a predictor for prevalent vertebral fractures, low bone mineral density, and vitamin D deficiency. Osteoporos Int. 2017;28:1659-65.

15. Tobias JH, Hutchinson AP, Hunt LP, McCloskey EV, Stone MD, Martin JC, et al. Use of clinical risk factors to identify postmenopausal women with vertebral fractures. Osteoporos Int. 2007;18:35-43.

16. Xu W, Perera S, Medich D, Fiorito G, Wagner J, Berger LK, et al. Height loss, vertebral fractures, and the misclassification of osteoporosis. Bone. 2011:48: 307-11.

17. Masunari N, Fujiwara S, Kasagi F, Takahashi I, Yamada M, Nakamura T. Height loss starting in middle age predicts increased mortality in the elderly. J Bone Miner Res. 2012;27:138-45.

18. Masunari N, Fujiwara S, Nakata Y, Nakashima E, Nalamura T. Historical height loss, vertebral deformity, and health-related quality of life in Hiroshima cohort study. Osteoporos Int. 2007;18:1493-9.

19. Takemitsu Y, Harada Y, Iwahara T, Miyamoto M, Miyatake Y. Lumbar degenerative kyphosis: clinical, radiological and epidemiological studies. Spine. 1988;13:1317-26.

20. Schwab FJ, Blondel B, Bess S, Hostin R, Shaffrey Cl, Smith JS, et al. Radiographical spinopelvic parameters and disability in the setting of adult spinal deformity. A prospective multicenter analysis. Spine. 2013;38:E803-12.

21. Lafage V, Schwab F, Patel A, Hawkinson N, Farcy JP. Pelvic tilt and truncal inclination. Two key radiographic parameters in the setting of adults with spinal deformity. Spine. 2009;34:E599-606.

22. Taillard W. Spondylolisthesis in children and adolescents. Acta Orthop Scand. 1954;24:115-44

23. Cobb JR. Outline for the study of scoliosis. Am Acad Othop Surg Instr Course Lect. 1948;5:261-75.

24. Pritchett JW, Bortel DT. Degenerative symptomatic lumbar scoliosis. Spine. 1993;18:700-3.

25. Robin GC, Span Y, Steinberg R, Makin M, Menczel J. Scoliosis in the elderly: a follow-up study. Spine. 1982;7:355-9. 
26. Murata Y, Takahashi K, Hanaoka E, Utsumi T, Yamagata M, Moriya H. Changes in scoliotic curvature and lordotic angle during the early phase of degenerative lumbar scoliosis. Spine. 2002;27:2268-73.

27. Diebo BG, Ferrero E, Lafage R, Challier V, Liabaud B, Liu S, et al. Recruitment of compensatory mechanisms in sagittal spinal malalignment is age and regional deformity dependent. Spine. 2015;40:642-9.

28. Kamimura M, Nakamura Y, Sugino N, Uchiyama S, Komatsu M, Ikegami S, et al. Associations of self-reported height loss and kyphosis with vertebral fractures in Japanese women 60 years and older; a cross-sectional survey. Sci Rep. 2016;6:29199.

29. Bernoist M. Natural history of the aging spine. Eur Spine J. 2003;12:S86-9.

30. Faraj SA, Holewin RM, van Hooff ML, de Kleuver M, Pellise F, Haanstra TM. De novo degenerative lumbar scoliosis: a systematic review of prognostic factors for curve progression. Eur Spine J. 2016;25:2347-58. https://doi.org/ 10.1007/s00586-016-4619-9.

31. Jimbo S, Kobayashi T, Aono K, Atsuta Y, Matsuno T. Epidemiology of degenerative lumbar scoliosis: a community-based cohort study. Spine. 2012;37:1763-70

32. Teraguchi M, Yoshimura N, Hashizume $\mathrm{H}$, Hashizume $\mathrm{H}$, Yamada H, Oka H, et al. Osteoarthr Cartil. 2017;25:1122-31.

33. Jarraya M, Guermazi A, Lorbergs AL, Brochin E, Kiel DP, Bouxsein ML, et al. A longitudinal study of disc height narrowing and facet joint osteoarthritis at the thoracic and lumbar spine, evaluated by computed tomography: the Framingham study. Spine J. 2018;18:2065-73.

34. Yoshimura N, Kinoshita H, Takijiri T, Oka H, Muraki S, Mabuchi A, et al. Association between height loss and bone loss, cumulative incidence of vertebral fractures and future quality of life: the Miyama study. Osteoporos Int. 2008;19:21-8.

35. Cho SK, Shin JI, Kim YJ. Proximal junctional kyphosis following adult spinal deformity surgery. Eur Spine J. 2014;23:2726-36.

36. Daniels AH, DePasse JM, Durand W, Hamilton DK, Passias P, Kim HJ, et al. Rod fracture after apparently solid radiographic fusion in adult spinal deformity patients. World Neurosurg. 2018;117:e530-7.

37. Liberman UA, Weiss SR, Broll J, Minne HW, Quan H, Bell NH, et al. Effect of oral alendronate on bone mineral density and the incidence of fractures in postmenopausal osteoporosis. The alendronate phase III osteoporosis treatment study group. N Engl J Med. 1995;333:1437-43. https://doi.org/10. 1056/NEJM199511303332201.

38. Nakamura T, Matsumoto T, Sumimoto T, Hosoi T, Miki T, Gorai I, et al. Clinical trials express: fracture risk reduction with denosumab in Japanese postmenopausal women and men with osteoporosis: denosumab fracture intervention randomized placebo controlled trial (DIRECT). J Clin Endocrinol Metab. 2014;99:2599-607.

39. Katzman WB, Vittinghoff E, Kado DM, Shafer AL, Wong SS, Gladin A, et al. Study of hyperkyphosis, exercise and function (SHEAF) protocol of a randomized controlled trial of multimodal spine-strengthening exercise in older adults with hyperkyphosis. Phys Ther. 2016;96:371-81.

40. Bansal S, Katzman WB, Giangregorio LM. Exercise for improving age-related hyperkyphotic posture: a systematic review. Arch Phys Med Rehabil. 2014; 95:129-40.

\section{Publisher's Note}

Springer Nature remains neutral with regard to jurisdictional claims in published maps and institutional affiliations.

Ready to submit your research? Choose BMC and benefit from:
- fast, convenient online submission
- thorough peer review by experienced researchers in your field
- rapid publication on acceptance
- support for research data, including large and complex data types
- gold Open Access which fosters wider collaboration and increased citations
- maximum visibility for your research: over 100M website views per year
At BMC, research is always in progress.
Learn more biomedcentral.com/submissions

